\title{
RESEARCH AND TECHNOLOGY DEVELOPMENT FOR CONSTRUCTION OF 3D VIDEO SCENES
}

\author{
Tatyana A. Khlebnikova
}

Dep. of Engineering Geodesy and Mine Surveying, Siberian State University of Geosystems and Technologies, 10, Plakhotnogo Str., Novosibirsk, 630108, Russian Federation - t.a.hlebnikova@ssga.ru

\section{Special Sessions, SpS 8}

KEY WORDS: technology, digital topographic plan, 3D video scene, digital elevation model (DEM), digital object model (DOM), digital photogrammetric station (DPS), 3D GIS

\begin{abstract}
:
For the last two decades surface information in the form of conventional digital and analogue topographic maps has been being supplemented by new digital geospatial products, also known as 3D models of real objects. It is shown that currently there are no defined standards for 3D scenes construction technologies that could be used by Russian surveying and cartographic enterprises. The issues regarding source data requirements, their capture and transferring to create 3D scenes have not been defined yet. The accuracy issues for 3D video scenes used for measuring purposes can hardly ever be found in publications. Practicability of development, research and implementation of technology for construction of 3D video scenes is substantiated by 3D video scene capability to expand the field of data analysis application for environmental monitoring, urban planning, and managerial decision problems. The technology for construction of $3 \mathrm{D}$ video scenes with regard to the specified metric requirements is offered. Technique and methodological background are recommended for this technology used to construct 3D video scenes based on DTM, which were created by satellite and aerial survey data. The results of accuracy estimation of 3D video scenes are presented.
\end{abstract}

\section{INTRODUCTION}

Over recent years analogue and digital topographic maps are becoming insufficient for many branches of Russian economy that needs more data on territories. Inadequate information value of a map and lack of geodetic education of some department officers with subsequent inability to read a map complicates and limits its use in some professional applications significantly. Such engineering challenges as computer-aided analysis of the topography, especially in the intensive development areas, require detailed digital data on spatial position of 3D objects.

New digital geospatial products, so-called 3D models of real objects in the area, have appeared recently. (Duda and Hart, 1976, Sokolov et al, 2006, Grubera et al, 2008). Production and application of these products were encouraged by the achievements of 3D computer graphics in 3D terrain modelling using GIS technologies. In scientific and technical publications there are different definitions and abbreviations, e.g. threedimensional virtual terrain models or $3 \mathrm{D}$ visualization, threedimensional digital models, 3D scenes, and three-dimensional scenes (Figure 1).

We have offered our own definition of a digital geospatial product, which is used in the article.

A three-dimensional video scene for measuring purposes is a three-dimensional digital model of the area that comprises a digital elevation model and a 3D digital model (models) for objects that are located in the area being under investigation, and is assigned for static and dynamic visualization, calculation and measurement using special GIS software.

The range of 3D-products is being expanded. Today visual digital urban models are the most demanded product. In many world's largest cities 3D spatial data are used for town planning, traffic management, noise protection, etc. (Sandra Haydeé González Garcia, Raúl Muñoz Salabarría et al, 2008).

In the Russian Federation the demand for 3D digital models has been growing in various fields. It is proved by a large number of Russian 3D digital city models that are available on different web-sites and in publications. 3D models provide terrain visualization and help on to choose the best solutions for various issues taking into consideration the details of a particular plot.

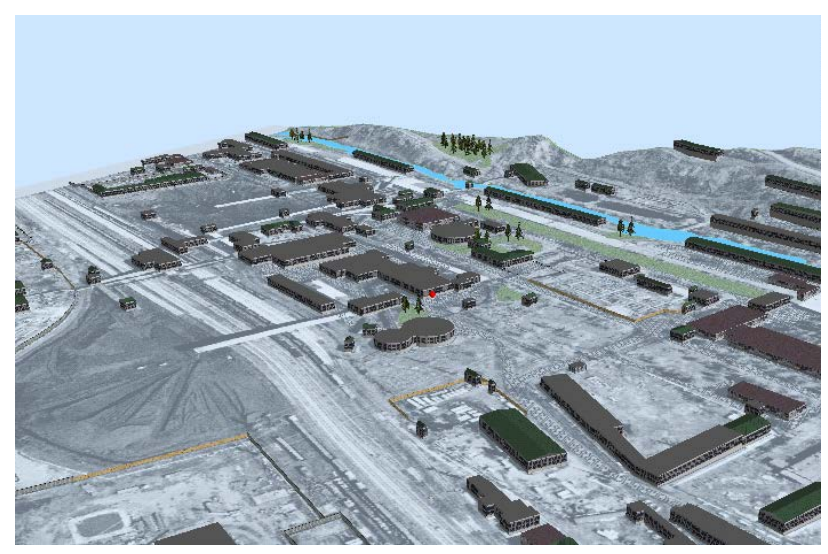

Figure 1. A 3D video scene

In many cases for a proper assessment of the chosen decision option and obtained results one should have reliable information not only about the position of spatial objects but their accuracy as well. Such data can be provided by high resolution satellite and aerial surveys, as well as by UAV surveys. In spite of the rapid development of Earth remote sensing procedures, aerial photography continues to be one of the main procedures for creation and updating large-scale maps, plans and DTMs.

Today practical works on 3D models generation are being carried out in Russia using high resolution satellite imagery, topographic maps and plans (digital or analogue). The construction of $3 \mathrm{D}$ video scenes by laser scanning data is also a promising technology. 


\section{RESEARCH GOAL}

Today the production units in the field of geodesy and cartography (JSC "Roscartography”, Moscow, Russia) as well as other organizations use both domestic and foreign digital photogrammetric systems (DPS) for processing satellite and aerial imagery. These systems are also implemented for acquisition of digital data on the topography to transfer them to GISs allowing maintaining three-dimensional video scenes (3D GIS). DPS with automated tools for stereoscopic collection of vector data for three-dimensional scenes construction came into use in recent years (Nekhin and Oleynik, 2011). Nevertheless, up till now there is no standardized technology to support the process. The issues regarding source data requirements, their acquisition and transferring to construct 3D scenes have not been solved yet. The accuracy assessment issues for 3D video scenes can hardly ever be found in publications.

Above mentioned defines both the relevancy of the scientific problem in the field of development and improvement of threedimensional terrain modelling for creation and study of new digital geospatial product that is a three-dimensional video scene for measuring purposes. This problem is under study at the Siberian State University of Geosystems and Technologies (SSUGT).

\section{REVIEW OF EXISTING TECHNOLOGIES}

The review of publications has shown that the existing technologies used for construction of three-dimensional video scenes can be divided into two types:

- Construction of 3D video scenes is carried out using 3D GIS tools by initial DEM and DOM obtained by various means for capture and processing of cartographic data, satellite and aerial imagery, laser scanning data, SAR interferometry, geodetic data, etc. In this case digital models should be converted into 3D GIS environment;

- 3D video scenes are constructed in the unified software package beginning from the initial data processing to the end-user product.

The primary data sources needed for the creation of a threedimensional video scene are maps, plans, geodetic observations, Earth remote sensing data, documented archives, Internet, etc. (Zhurkin and Shaitura, 2009). Generalization, based on the scales and territory coverage using remote sensing data, was made by Berlyant (Berlyant, 1996).

The classification of surveys, the results of which can serve as the source for getting 3D scenes of various spatial ranges (levels), is given in Table 1. This classification is based on the analysis made by Berlyant (Berlyant, 1996) and Zhurkin (Zhurkin, 2009).

\begin{tabular}{|c|c|c|}
\hline Scale of survey & $\begin{array}{c}\text { Horizontal and vertical } \\
\text { accuracy } \\
\mathrm{m}\end{array}$ & Range \\
\hline $\begin{array}{c}1: 10,000,000- \\
1: 500,000\end{array}$ & $\begin{array}{c}1000, \\
\text { from } 100 \text { to } 50\end{array}$ & Global \\
\hline $1: 500,000-1: 100,000$ & from 500 to 50,10 & Regional \\
\hline $1: 200,000-1: 50,000$ & up to 5, from 5 or higher & Local \\
\hline
\end{tabular}

Table 1. Classification of surveys as DTM source data

Table 1 shows that it is advisable to construct 3D video scenes using only high resolution satellite and aerial imagery starting from the local level. Table 2 shows a relationship between spatial ranges and aerial imagery scales.

\begin{tabular}{|c|c|}
\hline Range & Scale of aerial imagery \\
\hline Regional & $1: 100,000-1: 20,000$ \\
\hline Sub-regional & $1: 50,000-1: 5,000$ \\
\hline Local & $1: 10,000-1: 1,000$ \\
\hline
\end{tabular}

Table 2. Classification of aerial imagery as DTM source data

Satellite and aerial surveys in Russia are still considered as higher priority in creating national spatial data infrastructure (Sokolov et al., 2006).

The processing of satellite and aerial surveys data is carried out by DPS using photogrammetric technologies. Advantages of photogrammetric technologies are high information capacity, positional accuracy of point coordinates and heights, as well as high automation level of up-to-date digital photogrammetric systems.

\section{TECHNOLOGY DEVELOPMENT}

In order to construct a three-dimensional video scene apart from the aerial survey data it is also necessary to use other sources such as field measurements and archive materials. A generalized flow chart for constructing three-dimensional video scenes by means of various data is presented in Figure 2 . According to this flow chart we draw conclusions that it is necessary to develop an integrated solution based on data integration taken from the state-of-the-art digital photogrammetric systems and GIS having capacities to deal with 3D video scenes (Khlebnikova, 2008).

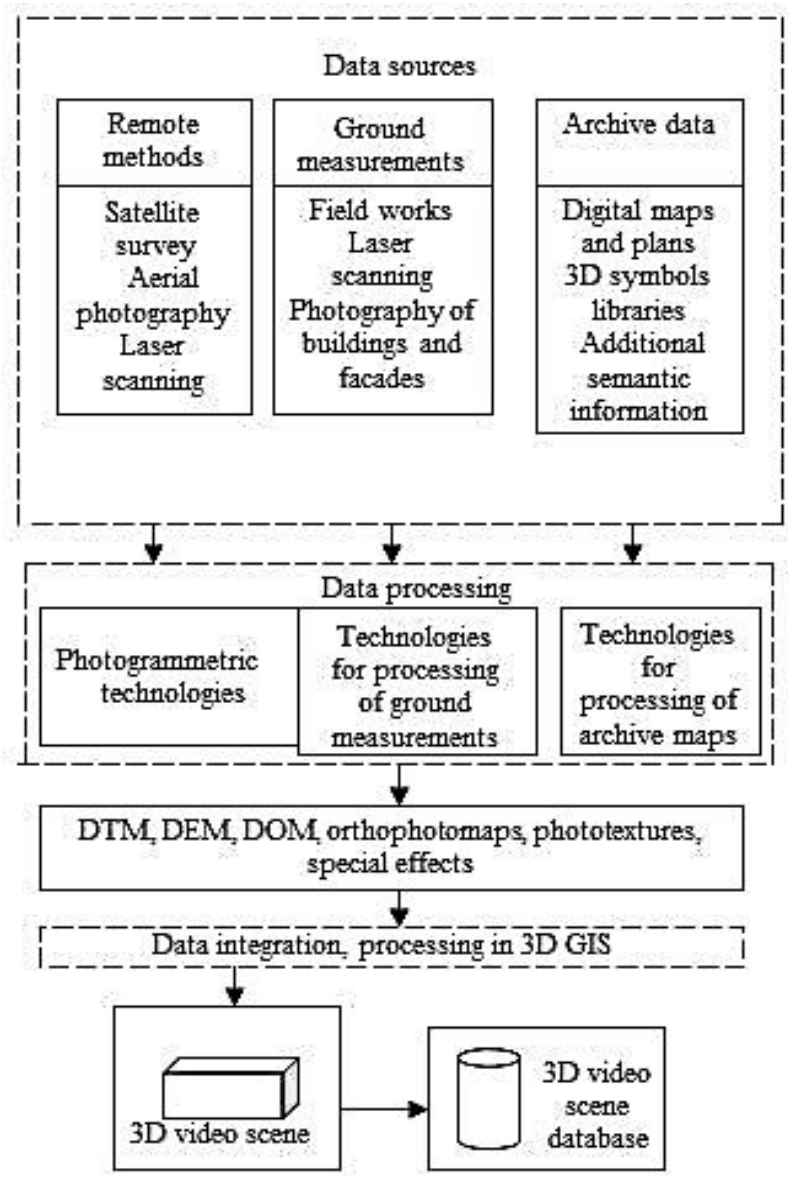

Figure 2. A generalized flow chart 
In this regard, the concept of 3D modelling of territories in terms of data integration is offered.

Theoretical justification of the concept is based on:

- Definition and content of the new digital geospatial product, that is a three-dimensional video scene for measuring purposes;

- Validation of methodology to optimize technological processes aimed at various data preparation for 3D video scenes formation including the following:

- Standardization of the requirements to the aerial survey data.

- Digital data capture guidelines for creating DPS-based DTMs as modified by requirements for 3D video scenes construction.

- Selection of hardware and software for the efficient technology development.

- Development of a composite flow diagram;

- Technique development for quality accuracy assessment of $3 \mathrm{D}$ video scenes.

Source data for the construction of 3D video scenes by GIS tools are raster images of ground surface, digital terrain models including a digital elevation model (DEM) and a 3D digital object model (Lisitskiy, 1988, Tikunov et al, 2008).

The terms 'DTM' and 'DOM' were introduced into practice more than three decades ago and included mainly topographic objects. At present the terms are fully adopted though the list of objects has expanded and now includes not only topographic features but also the natural phenomena and processes (clouds, fog, and snow cover), virtual objects (borders), traffic, and legends within the limits of the region of interest.

If we compare the life and utilization cycles for analogue and digital topographic maps and plans on one hand and 3D products on the other hand, it will be fair to say that the latter are much younger. However, they have been known and used for more than two decades. So here and elsewhere the term "young" means "up-to-date and contemporary".

DTMs will be used to construct three-dimensional video scenes needed for solving analytical and computing tasks but a vector topological model with three-dimensional data is preferable.

In order to develop the technology for constructing threedimensional video scenes, it is necessary to specify requirements to the source data, as well as those of to the content and the accuracy of the end-user product - a threedimensional video scene.

Thus, we need to summarize the following conditions making possible the creation of DTMs and meeting the requirements for the further construction of three-dimensional video scenes:

- A digital terrain model should include both DEM and DOM (natural and man-made objects). According to the terrain features the DEM must be presented in the form of regular altitude matrix for the terrain with subdued relief and triangulated irregular network for the terrain with welldefined relief.

The size of regular altitude matrix element depends on the required DEM scale.

The DOM is formed by digital topographic data. The object heights should be presented in the form of absolute or relative values. The relative height is one of the semantic information features.

Semantic information must also include the information about materials and other characteristics specifying the visual appearance of objects. It gives a possibility hereafter, when modelling 3D scenes in 3D GIS, to provide relatively photorealistic images of 3D objects using standard texture libraries. In this case there is no need to get a detailed phototexture for each object or their groups. When creating a unique
DOM (historical, architectural, etc.), the detailed photo-textures are required.

- The parameters of satellite and aerial surveys (flight scale, satellite imagery resolution) must be sufficient for the creation of DTM no less than 1:10,000;

- 3D video scene texture should be obtained using aerial and ground survey data;

- The DEM and DOM accuracy must not be less than the required positional accuracy of objects and contours within $3 \mathrm{D}$ video scenes. The required accuracy is expressed by mean errors.

Certain types of objects and contours on the digital model that are the most important for the end users or customers can be presented with the higher accuracy than required.

Generally, DTM content complies with or is close to the map of the corresponding scale. Depending on the 3D video scene application, the details of content elements and objects will be different.

Here we investigate the major challenges causing at the offered technology development.

When creating DEM and DOM by photogrammetric technologies and for their consequent use in 3D GIS, there appears the task of integrated correlation of DPS-based 3D terrain models on the one hand and 3D terrain models created within the inner structures of 3D GIS on the basis of input spatial data exported from DPS on the other hand. Besides consequent information support the solution of the task requires: Besides the existence of corresponding information support, this problem solution requires the following:

- Development of additional requirements to the classification system and its content, regulations concerning DPS-based digital data capture for the relief and objects.

- Identity verification of DPS-based DEMs and DOMs with those of created in 3D GIS, or in other words, determination of the final 3D video scene accuracy.

As follows from the analysis of a number of software tools and publications, the software requirements have been specified for $3 \mathrm{D}$ video scenes construction. These software tools should provide:

- Construction of a 3D video scene including a digital elevation model and object models with attributes according to thematic layers;

- 3D video scene visualization, point coordinate and height measuring on the terrain surface and objects with a required accuracy;

- Raster image overlay on a 3D video scene;

- Objects texturing;

- 3D video scene data storage.

Therefore, for the research and technology development the following software tools were chosen for construction of threedimensional video scenes:

- GIS ArcGIS (ESRI) and its application 3D Analyst;

- ERDAS IMAGINE - Virtual GIS;

- GIS “Map 2011", as a part of GIS "Panorama”, widely used in the Russian geo-industry.

The practical experience has shown that dealing with the only 3D DTMs has some limiting disadvantages. Combining digital topographic maps and plans, and 3D video scenes will allow determination of values for point coordinates and heights of area object of interest on a digital map by the well-recognized objects with the required accuracy.

In accordance with the aforesaid, the technology for construction of 3D video scenes consists of the following steps (Zhurkin and Khlebnikova, 2010, 2012): 
- Creation of DEMs and DMOs, digital maps (plans), orthophotomaps using high resolution satellite and aerial imagery according to the well-known flow charts;

- Creation of DEMs and DMOs and their compliance by means of 3D GIS;

- Creation of a three-dimensional video scene in 3D GIS.

\section{TECHNOLOGY RESEARCH}

Experimental studies have been performed according to the developed technology using the results of aerial photography (flight scale $-1: 8,000$, camera focal length $-153 \mathrm{~mm}$, frame size $23 \times 23 \mathrm{~cm}$ ) of three objects located an even land of Tyumen Region. This area is characterized by rural built-up environment, small timberlands and meadowlands.

Spatial data collection for construction of 3D scenes was performed by the DPS "Delta" Software (TSNIIGAiK, Moscow) and PHOTOMOD software (Racurs Company, Moscow). The mentioned DPSs help not only to create digital topographic maps, plans, models, and orthophotomaps, but other digital products as well.

3D video scenes were constructed in three 3D GIS environment: GIS “Map 2011”, Virtual GIS, and 3D Analist.

Photogrammetric control densification was performed for each object; stereoscopic models were built; orthophotomap (at a scale of scale 1:2,000) was created. Data capture for a DOM was performed by layers in accordance with the classifier formed in DPS environment (or 3D GIS) on the basis of the existing classifier template for the specified scale on the basis of topographic object composition. Data capture for a DEM was made by contour lines with $1 \mathrm{~m}$ interval or pickets in network nodes with the specified size and distinguished land forms. Digital data conversion for DEM and DMO into export formats, their import into appropriate 3D GIS were carried out.

A digital elevation model in each 3D GIS is obtained in the form of a regular altitude matrix and triangulated irregular network for GIS “Map 2011”, 3D Analist.

Matrix element size in constructing a 3D video scene by software tools GIS “Map 2011” and 3D Analist was set for the following values: $1,3,5,10,20,30 \mathrm{~m}$, by means of Virtual GIS $-1,5,10,20 \mathrm{~m}$.

The creation of 3D object models was performed by means of 3D GIS tools. The metrical accuracy analysis of threedimensional video scenes has been done for each object with regard to the following:

- Accuracy estimation was performed by control point heights because horizontal coordinates of DPS-based DTM's points are not changed after their import to 3D GIS;

- Well-recognized points on the ground surface, construction bottom and roof corners were chosen as control points.

\section{RESEARCH RESULTS}

When analyzing the results of accuracy estimation for each object in the form of height discrepancies, mean and RMS error values of model control point heights were obtained. The results of accuracy estimation for one of the objects in Tyumen Region are presented in Tables 3-5 and in the diagram (Figure 3).

The analysis of three-dimensional video scenes was carried out depending on 3D GIS software tools, source data forms for DEM creation (contour lines, regular altitude matrix, triangulated irregular network), and land forms.

Thus, for the even land the mean errors in altitude for control points from GIS "Map 2011", VirtualGIS and 3D Analist, are virtually of the same order for DEM, the regular altitude matrix with the matrix element size of 1-20 m, and for DEM in the form of triangulated irregular network. At the same time a disk storage space for the matrix data is increasing significantly with the decreasing of the matrix element size. For a hilly terrain the mean errors in height differences between control points from GIS "Map 2011" and 3D Analist are virtually the same for DEM in the form of triangulated irregular network and for DEM in the form of the regular altitude matrix with the matrix element size of $1 \mathrm{~m}$. The analysis of DEM accuracy for one of the three objects located in residential zone and industrial site showed that height discrepancies between control points (located on construction corners or close-located points) are within $0.5-1.0 \mathrm{~m}$.

\begin{tabular}{|c|c|c|c|c|c|}
\hline $\begin{array}{c}\text { Number of } \\
\text { points n, } \\
\text { mean and } \\
\text { RMS errors, } \\
\mathrm{m}\end{array}$ & \multicolumn{4}{|c|}{ Matrix element size, m } & \multirow{2}{*}{ TIN } \\
\cline { 2 - 5 } & 1.0 & 5.0 & 10.0 & 20.0 & \\
\hline $\mathrm{n}$ & 22 & 22 & 22 & 22 & 22 \\
\hline Mean error & 0.38 & 0.38 & 0.39 & 0.43 & 0.38 \\
\hline RMS error & 0.48 & 0.48 & 0.51 & 0.54 & 0.49 \\
\hline
\end{tabular}

Table 3. The results of vertical positional accuracy estimation of control points located on the ground surface and at the bottom corners of construction in GIS “Map 2011”

\begin{tabular}{|c|c|c|c|c|}
\hline \multirow{2}{*}{$\begin{array}{c}\text { Number of } \\
\text { points n, } \\
\text { mean and RMS } \\
\text { errors, } \mathrm{m}\end{array}$} & \multicolumn{5}{|c|}{ Matrix element size, $\mathrm{m}$} \\
\cline { 2 - 5 } & 1.0 & 5.0 & 10.0 & 20.0 \\
\hline \multicolumn{5}{|c|}{ Points on the ground surface and at the bottom corners of } \\
construction \\
\hline $\mathrm{n}$ & 22 & 22 & 22 & 22 \\
\hline Mean error & 0.42 & 0.40 & 0.42 & 0.45 \\
\hline RMS error & 0.52 & 0.50 & 0.54 & 0.56 \\
\hline & \multicolumn{5}{|c|}{ Roof corner points of construction } \\
\hline $\mathrm{n}$ & 18 & 18 & 18 & 18 \\
\hline Mean error & 0.40 & 0.40 & 0.46 & 0.40 \\
\hline RMS error & 0.47 & 0.50 & 0.55 & 0.49 \\
\hline
\end{tabular}

Table 4 . The results of vertical positional accuracy estimation of control points obtained by Virtual GIS

\begin{tabular}{|c|c|c|c|c|c|c|}
\hline $\begin{array}{c}\text { Number of } \\
\text { points n, } \\
\text { mean and RMS } \\
\text { errors, } \mathrm{m}\end{array}$ & \multicolumn{7}{|c|}{ Matrix element size, m } & \multirow{2}{*}{ TIN } \\
\cline { 2 - 7 } & 1.0 & 3.0 & 5.0 & 10.0 & 20.0 & \\
\hline Points on the ground surface and at the bottom corners of \\
construction \\
\hline $\mathrm{n}$ & 26 & 26 & 26 & 26 & 26 & 26 \\
\hline Mean error & 0.40 & 0.40 & 0.41 & 0.40 & 0.40 & 0.40 \\
\hline RMS error & 0.51 & 0.50 & 0.52 & 0.50 & 0.50 & 0.50 \\
\hline
\end{tabular}

Table 5. The results of vertical positional accuracy estimation of control points obtained by 3D Analist 


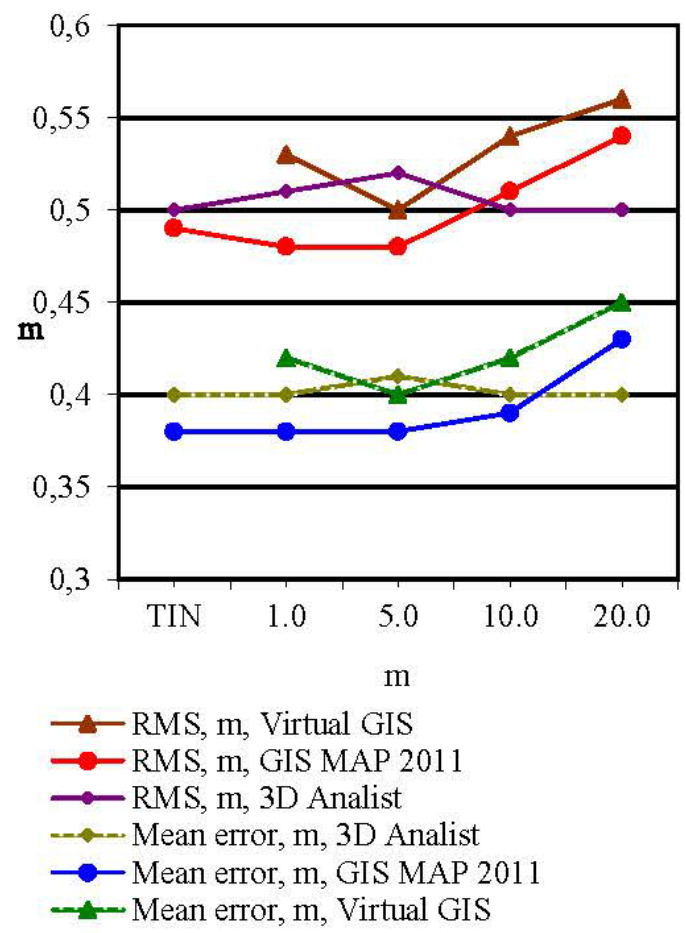

Figure 3. A diagram of the results of vertical positional accuracy estimation of control points located on the ground surface and at the bottom corners of construction for GIS "Map 2011”, Virtual GIS and 3D Analyst

According to the results of experimental investigations, the recommendations were specified for source data preparation, digital data capture, and selection of software.

\section{CONCLUSION}

We have developed the technique for 3D territory modelling on the basis of integrating data obtained by means of advanced digital photogrammetric systems and 3D GIS which are able to deal with 3D video scenes in creating geospatial products, for example, a three-dimensional video scene used for measuring purposes.

Besides, we developed the technology and recommended it for the construction of 3D video scenes using DTM data taking into account specified requirements to source data and a 3D video scene for measuring purposes. DTM was created using satellite and aerial surveys data.

3D video scenes were constructed in three 3D GIS environment: GIS “Map 2011”, Virtual GIS, and 3D Analist. The results of their accuracy estimation were presented.

Based on the research performed, the guidelines were drawn up for:

- Preparation of various data types to form the 3D video scenes for measuring purposes;

- Satellite and aerial survey data;

- Contents, accuracy and DTM;

- Rules for digital data capture used to create DPS-based DTM;

- Choice of hardware and software tools.

We are planning to use UAV aerial survey data for construction of $3 \mathrm{D}$ video scenes in the near future.

\section{REFERENCES}

Berlyant, A.,1996. Geoikonika (Geoiconics), Moscow. (In Russian).

Duda, R., Hart, P., 1976. Raspoznavaniye obrazov i analiz stsen (Images identificationa and scenes analysis), Moscow. (In Russian).

Grubera, M., Ponticellia, M., Bernöggera, S., Leberlb, F., 2008. Ultracamx, the large format digital aerial camera system by vexcel imaging/Microsoft. XXI Congress 3-11 July 2008. Beijing China. PROCEEDINGS Volume XXXVII, Part B1, TC I. pp. 665-670. - 1 disc (DVD+R).

Khlebnikova, T., 2008. Tekhnologiya postroyeniya izmeritelnykh tryokhmernykh videostsen po dannym TsMM: problemy i puti resheniya (The technology of DTM- based 3D video scenes construction for measuring purposes: problems and their solutions). Geodesy and Cartography, No 2, pp. 4446. (In Russian).

Lisitskiy, D., 1988. Osnovniye printsipy zifrovogo kartographirovaniya mestnosty (General principles of digital terrain mapping), Moscow. (In Russian).

Nekhin, S., Oleynik, S., 2011. Avtomatizatsiya fotogrammetricheskogo sbora tryokhmernoy informatsii na TsFS (Automation of DPS-based capture of three-dimensional data). News of Higher Educational Institutions Geodesy and Aerophotography. No. 2, pp.70-74. (In Russian).

Sandra Haydeé González Garcia, Raúl Muñoz Salabarría, Alián Mayet Valdés, Dunia Suárez Ferreiro, Bernardino Deni Díaz Rodríguez. Modelling of Urban Environments. XXI Congress 311 July 2008, Beijing China. PROCEEDINGS Volume XXXVII, Part B5, TC V. pp. 707-710. - 1 disc (DVD+R).

Sokolov, I., Filatov, V., Martynenko, A et al., 2006. Vazhnejshiye fundamentalniye i prikladniye problemy geoinformatiki (Major basic and applied geoinformation science problems). Geodesy and Cartography, No 11, pp. 47-56. (In Russian).

Tikunov, V., Kapralov, E., Koshkarev, A. et al.; 2008a. Geoinformatics in 2 volumes. Vol.1: students' book for Higher Educational Institutions. Moscow. (In Russian).

Zhurkin, I., Khlebnikova, T., 2010. Resultaty eksperimentalnykh issledovaniy tekhnologii polucheniya izmeritelnoy trekhmernoy videostseny po materialam aerokosmicheskikh syomok (Experimental results regarding technology for construction of 3D video scenes using satellite and aerial surveys data). Geodesy and Cartography, No7, pp. 27-31. (In Russian).

Zhurkin, I., Khlebnikova, T., 2012. Tsifrovoye modelirovaniye izmeritelnykh tryokhmernykh videostsen (Digital modelling of 3D video scenes for measuring purposes). Novosibirsk: SSAG, 246. pp. 38-45. (In Russian).

Zhurkin, I., Shaitura, S., 2009. Geoinformatsionniye sistemy (Geoinformation systems), Moscow. (In Russian). 